\title{
Determining Variations in Access to Public Hospitals in Makkah, Kingdom of Saudi Arabia: A GIS-Based Approach
}

\author{
Mazen Baazeem ${ }^{\mathrm{a}, \mathrm{b}} \quad$ Marc Tennant $^{\mathrm{a}} \quad$ Estie Kruger $^{\mathrm{a}}$ \\ anternational Research Collaborative - Oral Health and Equity, School of Human Sciences,

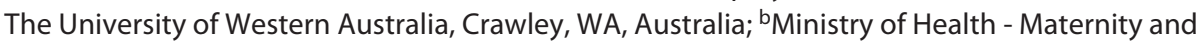 \\ Children's Hospital, Makkah, Saudi Arabia
}

\section{Keywords}

Geographical information systems · Hospital accessibility · Population distribution · Drive-time $\cdot$ Public health

\begin{abstract}
Background: Variation in gaining accessibility to public hospitals in Makkah, Saudi Arabia, has not been investigated before. Good access to public health facility will lead to improvements in the population's health. Maps and geographical information system (GIS) technology can provide assistance to address public health coverage issues. Aims: This study aimed to use GISs to identify spatial accessibility to hospitals in Makkah, based on the radius and drive-time analysis technique. Method: Using Quantum GIS (QGIS), a geodatabase was created to include 8 public hospitals' locations and data of population distribution across the city. Buffer zones at 2.5, 5, 7, and $10 \mathrm{~km}$ radius from the public hospitals were identified and examined. Results: The findings revealed that most of the health facilities across the suburbs of Makkah were located in urban areas, while rural and remote areas were neglected. Conclusion: Public health facilities were distributed relative to high population density. Onethird of the city's population does not have proper access to healthcare services.

(c) 2021 The Author(s)

Published by S. Karger AG, Basel
\end{abstract}

\section{Introduction}

Hospitals are an essential pillar of health care. Fair distribution of healthcare facilities is one of the main goals of any health system. The optimal allocation of medical resources aims to match healthcare provision with social and economic demands by improving access to healthcare services, reducing waiting time, satisfying the population's medical and health needs, and enhancing the overall quality of life [1]. An important consideration for decision-makers, planners, and healthcare systems is to investigate and examine the spatial relationship between healthcare service locations and geographic accessibility to those services [2-4]. The most appropriate location of healthcare services is crucial to meet the population's health needs. The location of new health services should be targeted to ease the inequality of health resources.

Several researchers have argued that healthcare accessibility tends to be far from equal across urban, suburban, and rural areas in the Kingdom of Saudi Arabia (KSA) [5-9]. However, there has been little detailed investigation of the spatial characteristics of healthcare services in Makkah's districts, specifically geographic patterns and accessibility. This research aimed to offer an overview of the spatial distribution of healthcare ser-
C 2021 The Author(s)

Published by S. Karger AG, Basel

This is an Open Access article licensed under the Creative Commons Attribution-NonCommercial-4.0 International License (CC BY-NC) (http://www.karger.com/Services/OpenAccessLicense), applicable to the online version of the article only. Usage and distribution for commercial purposes requires written permission.
Mazen Baazeem

International Research Collaborative - Oral Health and Equity

School of Human Sciences, The University of Western Australia

35 Stirling Highway, Crawley, WA 6009 (Australia)

mazen.baazeem@ research.uwa.edu.au 


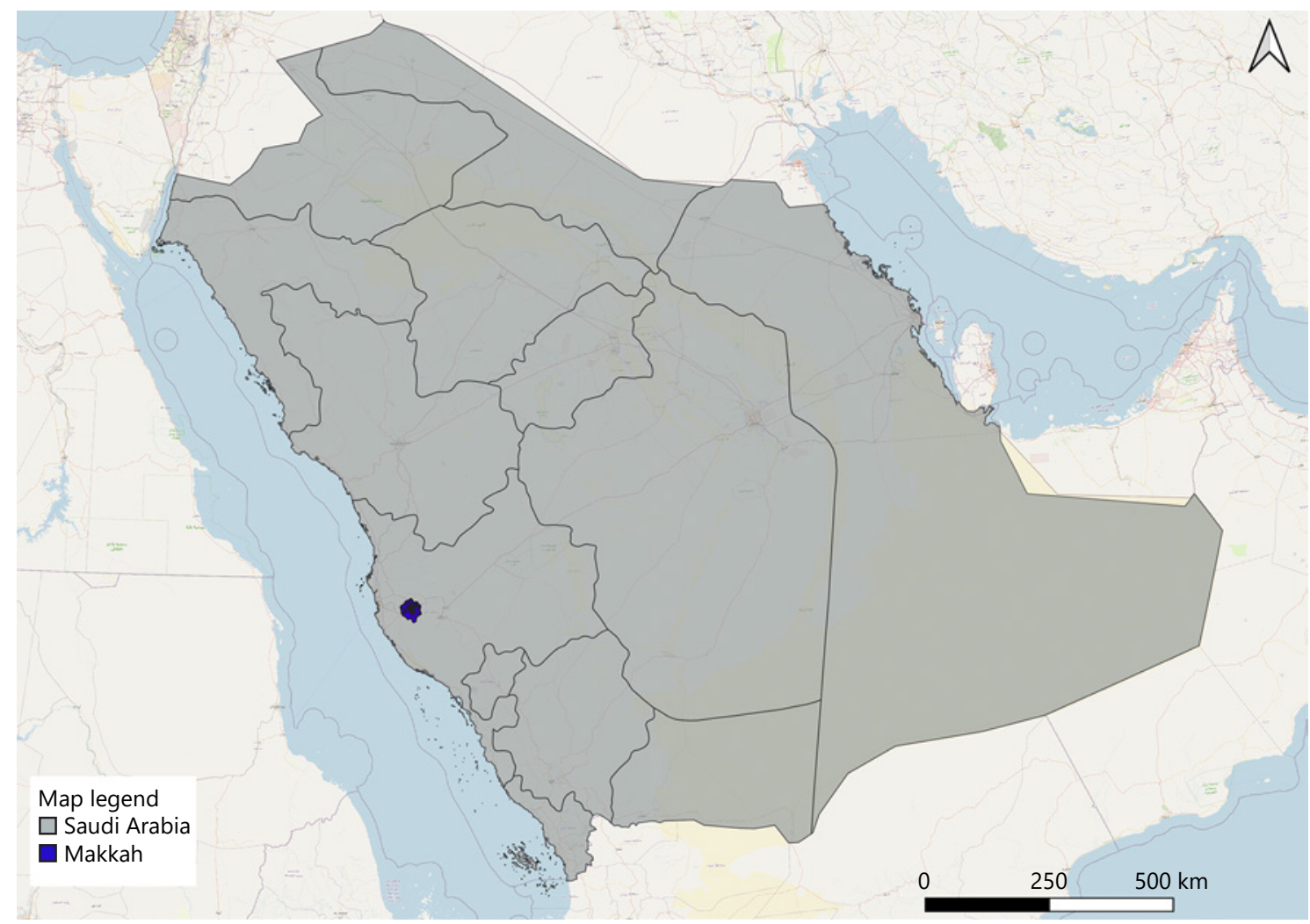

Fig. 1. A map of Saudi Arabia with the location of Makkah.

vices and to investigate the relationship between healthcare facility locations and the population size of Makkah's districts.

\section{Methods}

Makkah, otherwise known as Mecca, is a city in the western region of the KSA and is one of the country's most important economic and cultural centres. As shown in Figure 1, Makkah is approximately $70 \mathrm{~km}$ from Jeddah and $450 \mathrm{~km}$ south of Medina. Makkah is known for its religious importance for Muslims. This is why millions of Muslims travel to the city on a regular basis. Hajj and Umrah, for example, is one of the religious journeys that drive vast amounts of traffic to this Saudi Arabian city every year. In 2019, the total number of pilgrims reached 2.5 million [10].

According to data provided by the Saudi General Authority for Statistics, the city is inhabited by around 1.535 million people [11]. On the other hand, the UN in its report has estimated that the city's population now stands at around 2.042 million [12]. The differences in data are because the official governmental data were collected in 2011 and have not been updated. A new census was planned in 2020, but due to the impact of COVID-19, the Saudi General Authority for Statistics has decided to postpone the census until further notice [13].
Modern geographical information system (GIS) techniques are used for their analytical capabilities to explore healthcare service delivery and examine whether there is a significant variation among districts in public health provision and accessibility. Eight public hospitals in Makkah were mapped against the population distribution, using a GIS-based method. These hospitals are (1) Ajyad Hospital, (2) King Faisal Hospital, (3) King Abdul Aziz Hospital, (4) Al Noor Specialist Hospital, (5) Hira Hospital, (6) Maternity and Children Hospital, (7) King Abdullah Medical City, and (8) Ibn Sena Hospital. The longitude- and latitude-based addresses for each of the identified hospitals in Makkah city were obtained from the Ministry of Health website. The study was limited to these 8 hospitals as they are all public health facilities, owned and controlled by the Ministry of Health. The location of the public hospitals and their respective areas of coverage were mapped according to the location of the areas within the city with the highest levels of population density (i.e., the biggest population clusters).

To effectively use GISs in displaying the area of coverage for each of the identified Makkah city hospitals in relation to the city's population clusters, random points were used, where 1 point represents 100 people and 2 points represent 200 people. Quantum GIS (QGIS) was used to place the population dots on the map, combined with the pinpointed location of the Makkah city public hospitals, and the 8 public hospitals' respective levels of accessibility were evaluated on 4 radiuses. Around each hospital, a buffer zone was drawn with a specified radius. The main differentiating 
Fig. 2. $2.5 \mathrm{~km}$ buffer zone.
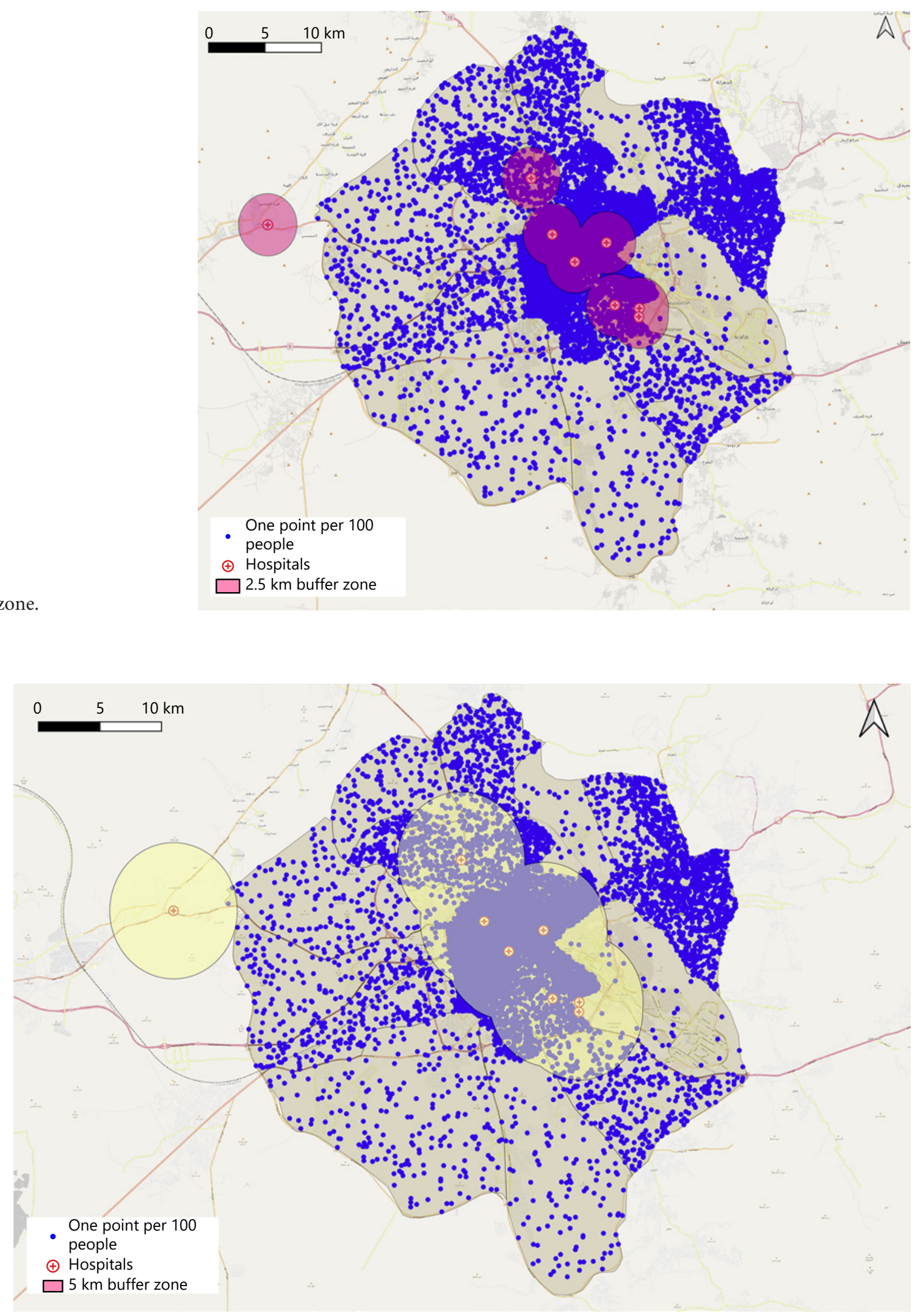

Fig. 3. $5 \mathrm{~km}$ buffer zone. 
Fig. 4. $7 \mathrm{~km}$ buffer zone.

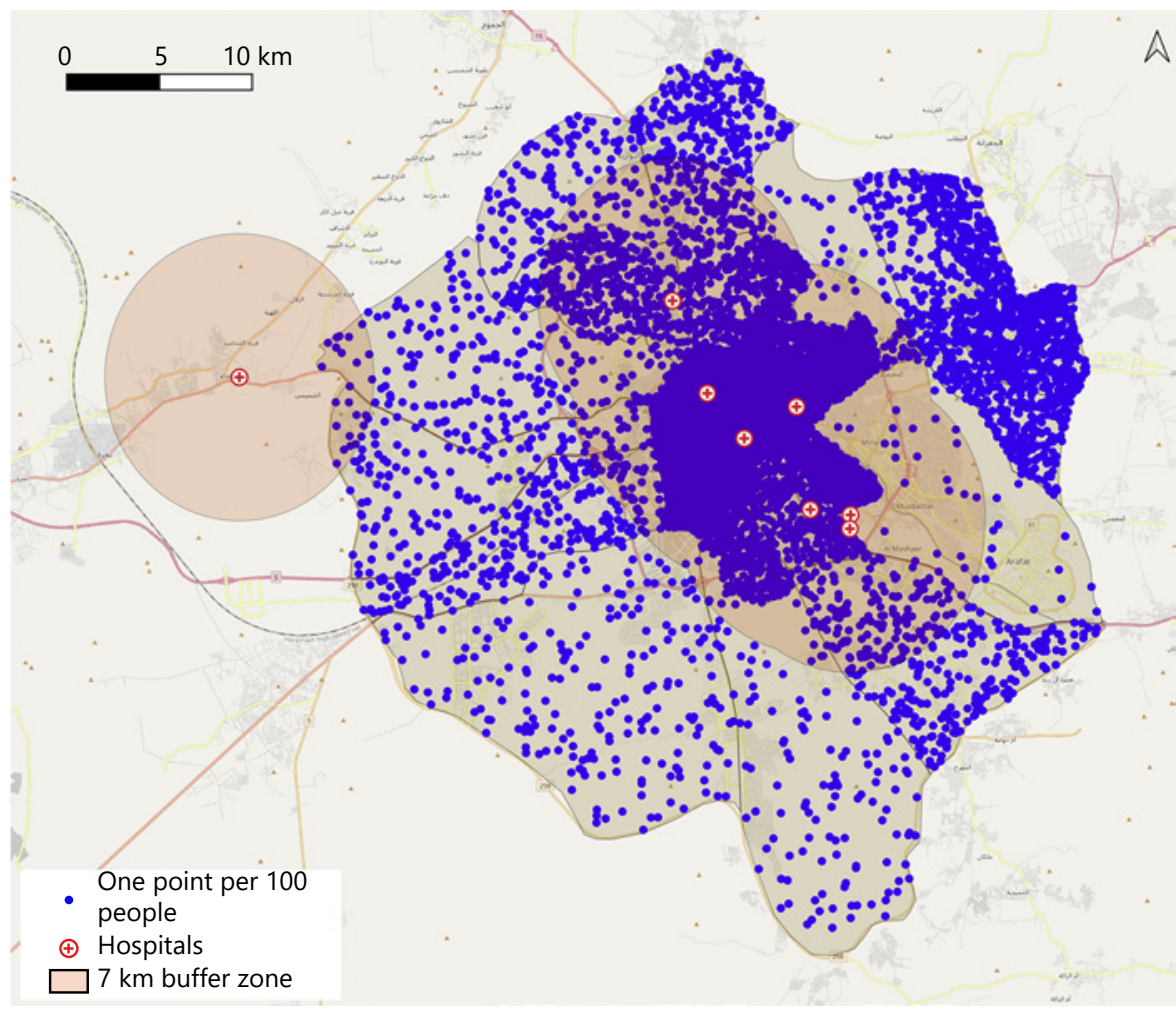

factor between these 4 levels of accessibility was their distance from the population clusters (the blue dots in the GIS-generated maps).

Buffer zones at $2.5 \mathrm{~km}$ (Fig. 2), $5 \mathrm{~km}$ (Fig. 3), $7 \mathrm{~km}$ (Fig. 4), and $10 \mathrm{~km}$ (Fig. 5) radius from the public hospitals were identified and examined. The hospital to population ratio was also ascertained by using the census data. The population data were obtained from the Saudi General Authority for Statistics. This was complemented by GIS data from Google Maps. All the data for this analysis were extracted from the integrated database in QGIS and imported to Microsoft Excel for processing.

\section{Results}

The results obtained from the QGIS for the current study are summarized in Table 1 . The number of people captured in this GIS-based analysis of healthcare service accessibility in Makkah, at the most generous level of accessibility (a 10-km radius from the nearest publicly funded hospital), was around 1.34 million (Fig. 5). The population of Makkah at the time was 1.53 million (as of 2011). In theory, this leaves around 170,000 individuals living in the city who, based on the most generous level of accessibility standards used in this study (a $10-\mathrm{km}$ radius) (Fig. 5), live too far away from the nearest publicly funded city hospital for it to be considered accessible.

Hospitals Distribution in Makkah by GIS
Table 1. Population distribution in each buffer zone

\begin{tabular}{lc}
\hline Distance/km & Population/100 \\
\hline 2.5 & 7,954 \\
5 & 11,718 \\
7 & 12,527 \\
10 & 13,433 \\
\hline Total & 15,144 \\
\hline
\end{tabular}

With a distance of a 7-km radius, 125,2700 individuals have access to healthcare service (Fig. 4). This will leave around 261,700 people out of healthcare service coverage.

The number of populations captured with a level of accessibility of $5 \mathrm{~km}$ radius is 117,1800 individuals, with nearly 342,600 people without healthcare service coverage (Fig. 3). Five kilometres can be considered a relatively accessible distance from a person's place of residence to the nearest public hospital within the city. Although the $2.5-\mathrm{km}$ radius is considered a small distance, more than half the population in Makkah lives in this buffer zone (Fig. 2), with a total number of 795,400 individuals. 


\section{Fig. $5.10 \mathrm{~km}$ buffer zone.}

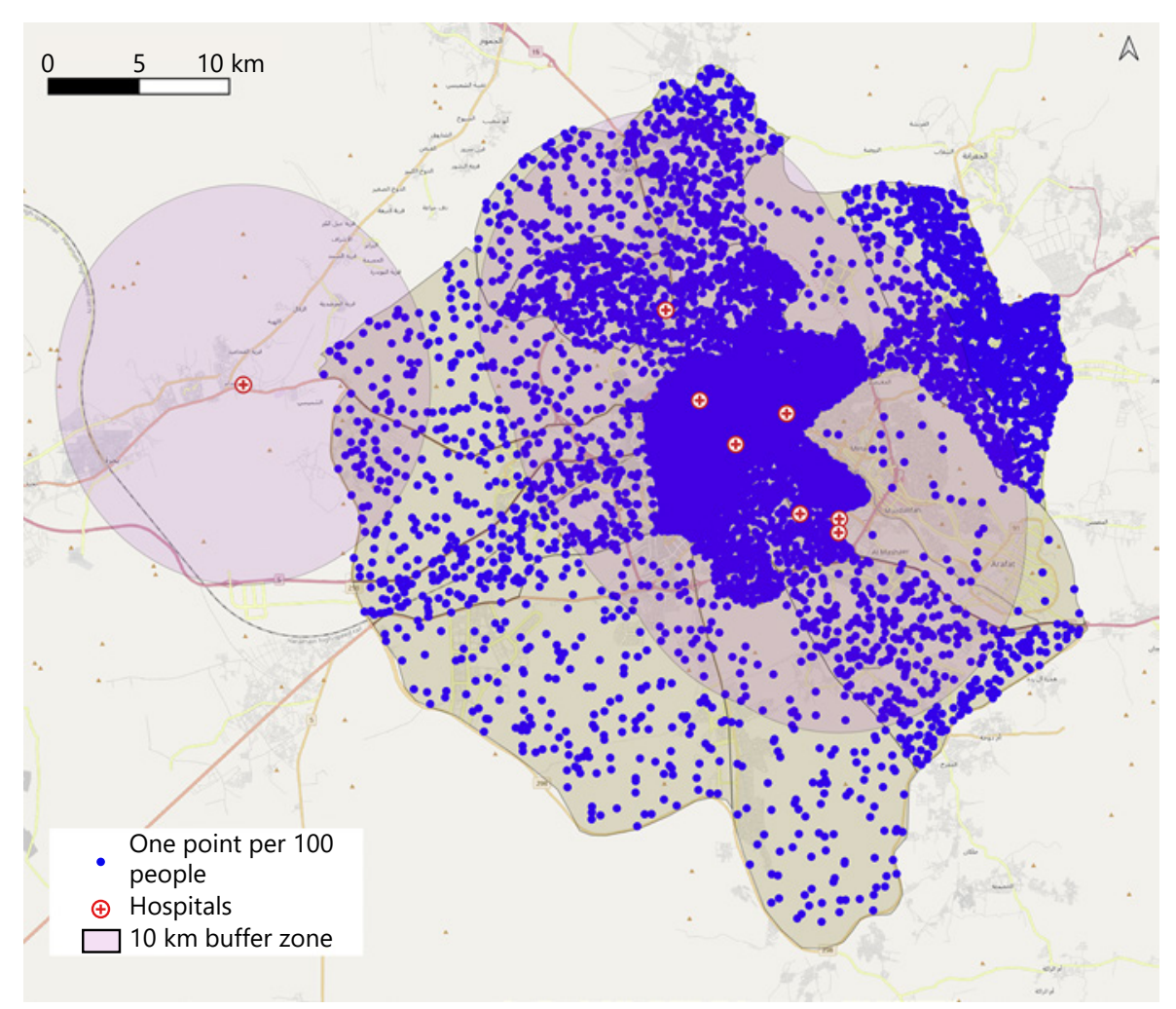

\section{Discussion}

Several researchers have argued that healthcare accessibility tends to be far from equal across urban, suburban, and rural areas in the KSA [5-9]. The current study focuses on the accessibility of healthcare services in the city of Makkah in the KSA using GIS-based methods. Using the model that was developed, in which there are 8 publicly funded city hospitals and 1.51 million people who have to be serviced, the ratio between hospitals and the number of people who should be served stands at 189,300. On the positive side, since most of the city's public hospitals are located in the city's urban core, $52 \%$ of the people living in the city live in an area that has a high level of healthcare service accessibility. On the negative side, this means that one-third of the city's population does not have proper access to healthcare services, as shown by the GIS-generated maps and map data. Therefore, the ideal scenario for these 8 hospitals, where the level of access to healthcare services is equal among the 1.51 million inhabitants of the city, is that they should be able to serve a population of 189,300 each. In reality, some publicly funded city hospitals are not placed ideally in relation to the population, as some are located close to each other.
A healthcare system that satisfies the availability and affordability requirements would be useless if a small number of people could access healthcare services [14]. Access to health care is critical to achieving a relatively stable state of health at both the individual and community levels. However, there are many barriers to healthcare accessibility, both for governments and citizens [15]. In the case of the KSA, where the government subsidizes the cost of health care, the barriers to healthcare accessibility tend to be much more pronounced in rural and remote areas than in urban and centrally located areas [16]. These barriers affect both the government entities who are trying to deliver the healthcare services where they are most required and the population who are trying to reach the subsidized public hospitals that can provide them with the medical and healthcare services they need.

There are a limited number of studies that have investigated the accessibility to public hospitals in the KSA. Similarly, few studies have investigated the accessibility to public hospitals and primary healthcare centres in other different cities, such as Jeddah and Riyadh [17, 18]. Only 1 study conducted in Makkah investigated the patient flows, catchment area, patient profile, and patient distribution models of 1 primary healthcare centre $(\mathrm{Ru}-$ 
saifa Medical Centre) that provides its services to 20,975 people living in 4 surrounding neighbourhoods [19]. The outcome revealed that health resource of the existing services did not match with the demand. However, the scope of this study was relatively narrow, being primarily concerned with 1 primary healthcare centre and with different aims and methods. This makes it hard to compare the results obtained from the current study with previous study results. Therefore, further research in this field would be of great benefit to better assess the accessibility to public health services in Makkah.

The most important limitation of the current study is that it was based on population data from 10 years ago, and it is unclear how changes in population numbers might affect the results. Therefore, more recent data are required to accurately assess the variations in access to public hospitals in Makkah. The public hospital located near the city's western border also reaches a much smaller number of people than those located in the city centre. The government of the KSA and the city of Makkah could focus their efforts on building more hospitals to service the north, south, and southwestern regions of the city.

\section{Conclusions}

This study sought to analyze variations in access to public hospitals by using the spatial distribution of hospitals in relation to the population density in Makkah. Based on the GIS-based maps that were generated and the governmental population estimates for the city of Makkah, most of the public hospitals are located in the urban core and central areas, providing an adequate level of access to health services for most people. Policymakers should consider the use of GIS techniques to identify the most appropriate locations when planning for new hospitals; this will contribute to an appropriate and more equitable geographic distribution of health services.

\section{Acknowledgement}

The authors thank Dr. Alla T. Alsharif for her help in getting the population data to this research project.

\section{Statement of Ethics}

This study did not require ethical approval since it does not involve any human or animal subjects.

\section{Conflict of Interest Statement}

The authors declare no conflict of interest.

\section{Funding Sources}

This study did not receive any specific grant from any funding agency from the public, commercial, or not-for profit sector.

\section{Author Contributions}

This research was designed by Mazen, Marc, and Estie. Data were analyzed by Marc and Mazen. Mazen wrote the original draft. The final draft was reviewed and edited by Estie. All authors read and approved the final manuscript.

\section{References}

1 Sharmin N, Neema M. A GIS-based multicriteria analysis to site appropriate locations of hospitals in Dhaka city. Hospital. 2013;8: 0-37.

2 Langford M, Higgs G. Measuring potential access to primary healthcare services: the influence of alternative spatial representations of population. Prof Geogr. 2006;58(3):294306.

3 Linard C, Gilbert M, Snow RW, Noor AM, Tatem AJ. Population distribution, settlement patterns and accessibility across Africa in 2010. PLoS One. 2012;7(2):e31743.

4 Perry B, Gesler W. Physical access to primary health care in Andean Bolivia. Soc Sci Med. 2000;50(9):1177-88.
5 Al-Ahmadi K, Al-Zahrani A, Al-Ahmadi S. Spatial accessibility to cancer care facilities in Saudi Arabia. Cambridge, MA: Esri Health GIS Conference; 2014.

6 Al-Hanawi MK, Alsharqi O, Almazrou S, Vaidya K. Healthcare finance in the Kingdom of Saudi Arabia: a qualitative study of householders' attitudes. Appl Health Econ Health Policy. 2018;16(1):55-64.

7 Alfaqeeh G, Cook EJ, Randhawa G, Ali N. Access and utilisation of primary health care services comparing urban and rural areas of Riyadh providence, Kingdom of Saudi Arabia. BMC Health Ser Res. 2017;17(1):106.
8 Almubark R, Basyouni M, Alghanem A, Althumairi N, Alkhamis D, Alharbi LS, et al Health literacy in Saudi Arabia: implications for public health and healthcare access. Pharmacol Res Perspect. 2019;7(4):e00514.

9 Mohammed A, Mohammad B, Navin I, Mansour A, Majdah Al K. Factors affecting access to oral health care among adults in Abha city, Saudi Arabia. J Int Soc Prev Community Dent. 2018;8(5):431-8.

10 Saudi General Authority for statistics. Hajj statistics 2019 - 1440. 2019.

11 Saudi General Authority for Statistics. The sixteenth services guide 2017: Makkah AlMokarramah Region Riyadh. 2017.

12 United Nations. The world's cities in 2018. 2018. 
13 Saudi Press Agency. Saudi GaStat: Suspension of Field Work for Saudi Census 2020 Project Until Further Notice Riyadh SPA; 2020. Available from: https://www.spa.gov.sa/ viewfullstory.php?lang=en $\& \quad$ newsid= 2047323.

14 Li Y, Vo A, Randhawa M, Fick G. Designing utilization-based spatial healthcare accessibility decision support systems: a case of a regional health plan. Decis Support Syst. 2017; 99:51-63.
15 Guagliardo MF. Spatial accessibility of primary care: concepts, methods and challenges. Int J Health Geogr. 2004;3(1):3.

16 Walker L. The right to health and access to health care in Saudi Arabia with a particular focus on the women and migrants. In: Toebes B, Ferguson R, Markovic MM, Nnamuchi O, editors. The right to health: a multi-country study of law, policy and practice. The Hague: T.M.C. Asser Press; 2014. p. 165-92.
17 Mansour S. Spatial analysis of public health facilities in Riyadh Governorate, Saudi Arabia: a GIS-based study to assess geographic variations of service provision and accessibility. Geo Spatial Inform Sci. 2016;19(1):26-38.

18 Murad AA. Using GIS for determining variations in health access in Jeddah city, Saudi Arabia. Int J Geo-Information. 2018;7(7):254

19 Murad AA. Creating a GIS application for local health care planning in Saudi Arabia. Int J Environ Health Res. 2004;14(3):185-99. 